\title{
Wearing Colored Glasses can Influence Exercise Performance and Testosterone concentration?
}

\section{(우(1) $(8)$}

\author{
Authors \\ André M. Londe1, Moacir Marocolo², Isabela Coelho Marocolo'1, James Fisher ${ }^{3}$, Octavio Barbosa Neto', \\ Markus Vinicius Campos Souza', Gustavo Ribeiro da Mota ${ }^{1}$
}

Affiliations

1 Human Performance and Sport Research Group, Department of Sport Science/Institute of Health Sciences, Federal University of Triangulo Mineiro, Uberaba, MG, Brazil

2 Institute of Biological Sciences, Department of Physiology, Universidade Federal de Juiz de Fora, Juiz de Fora, Brazil

3 Centre for Health, Exercise \& Sport Science, Southampton Solent University, Southampton, United Kingdom of Great Britain and Northern Ireland

\section{Key words}

hormones, color perception, ergogenic, exercise \& sport, soccer

received 06.02 .2018

revised 14.03.2018

accepted 22.03.2018

Bibliography

DOI https://doi.org/10.1055/a-0601-7250

Sports Medicine International Open 2018; 2: E46-E51

(c) Georg Thieme Verlag KG Stuttgart · New York

ISSN 2367-1890

\section{Correspondence}

Dr. Gustavo Ribeiro da Mota, PhD

Federal University of Triangulo Mineiro

Department of Sport Sciences/Institute of Health Sciences

Av. Frei Paulino, $\mathrm{n}^{\circ} 30$ - Abadia

UBERABA, 38025-180
Brazil

Tel.: + 34/3318 5931, Fax: + 34/33185931

grmotta@gmail.com

\section{ABSTRACT}

Perception of red color is associated with higher testosterone concentration and better human performance. Thus, we evaluated the acute effects of wearing colored-lens glasses on the YoYo intermittent endurance exercise test 2 (YoYolE2) performance indicators and testosterone concentration. Ten soccer players performed three YoYoIE2 (counterbalanced crossover) wearing colorless (control), blue- or red-lensed glasses (2-4 days of rest in between). YoYolE2 performance did not differ among the trials ( $p>0.05)$, but blood testosterone increased post-exercise in red compared to red baseline (red $=14 \%$, effect size $=0.75)$. Analysis showed faster heart rate recovery $(p<0.05)$ at 1 min post-test for blue compared to red lenses. Rating of perceived exertion and blood lactate concentration did not differ $(p>0.05)$ among the trials. Wearing red-colored lenses during high-intensity intermittent exercise increased testosterone concentration, but do not influence performance.

\section{Introduction}

Minimal gains can determine success in sports/exercise performance [29], one reason why researchers have studied several different strategies like proper diet [23], pre-exercise interventions [21,37-40], additional training methods [10,42], garments [15] among others. Except for visual impairment, various colors are commonplace as part of everyday human life (e. g., traffic lights, billboards, commercial business signs). Similarly, the environment surrounding sports competitors is colorful as well (e.g., uniforms, clothing of spectators). Despite this abundant prevalence of color, the influence of color on human physical performance is unclear.

Hill \& Barton (2005) associated wearing the color red with success in combat sports (i. e., higher possibility of winning in wearing red garment). The authors hypothesized that wearing red could 
enhance the testosterone response and thereby improve performance [28]. However this testosterone hypothesis was derived from animal-based research [1,48], and furthermore, Hill \& Barton (2005) did not measure testosterone in their study. An active choice of red by individuals with high testosterone levels in a cognitive stressor test was found suggesting a link in a competitive environment. Nevertheless, the authors did not measure exercise performance data [17]. Hackney examined the testosterone responses of 10 men to a single maximum incremental exercise test (cycle ergometry) to determine the influence of red color on hormonal response and performance. He found no effects on power output, oxygen consumption, the rate of perceived exertion or testosterone concentration [26].

The rationale of these studies $[17,26,28]$ was that "being or wearing red" could affect opponents' perceptions of red competitors as being of high quality. A body of research in this area has considered soccer performance and reported equivocal results. For example, soccer goalkeepers reported more positive percieved characterstics facing a penalty taker wearing a red compared to a white shirt [24], whereas penalty takers facing a goalkeeper wearing red scored fewer penalty kicks compared to when facing a goalkeeper wearing blue or green [25]. Another study reviewed the success of English soccer teams wearing red and reported greater success compared to other colors over a 55-year period [2]. However, García-Rubio, et al. [20] detailed that the same was not true for Spanish soccer teams. Other authors suggested that some of the effect of color on performance might relate to percpetual distortion caused by moving objects. To test this hypothesis, they assessed participants playing a computer game where they were trying to hit, escape from or outmaneuver certain objects of specific color. Their results suggested that red objects were easier to hit than other colors, but there were no differences in avoidance of objects of specific color [50].

Perhaps an alternative way to accurately test color effects on performance is to perform the tests in a colorful surrounding environment. In this sense, only one study has evaluated endurance performance in randomized trials using different goggles (colored lenses) and found that the color blue improved performance [19]. Although Fisher et al. [19] performed a well-controlled study, they also had no physiological measurement. In their study [19] the colors of blue and red were chosen because of their relationship at contrasting frequencies and wavelengths (e. g., red, $\sim 450 \mathrm{THz}$ and $\sim 660 \mathrm{~nm}$, respectively) and blue, ( $\sim 640 \mathrm{THz}$ and $\sim 470 \mathrm{~nm}$, respectively). Although the authors hypothesized that the blue might have a calming effect and the red an increased arousal level, the authors reported that the blue color condition improved muscular endurance performance compared only to the control condition (i. e., not greater than the red condition). As such, they could not explain the reason behind "blue color" ergogenic effect.

No study has investigated the effects of different colors on specific physiological tests related to team sports performance, and specificity is fundamental for sports performance [43]. For example, the YoYo intermittent endurance test level 2 (YoYolE2) is reproducible and highly correlated to high-intensity running performance in soccer matches [5]. Because high-intensity exercise generates higher biological stress [31] and YoYolE2 produces maximal responses for different levels of fitness [4, 33, 35], the YoYolE2 could be a model to investigate specific performance concomitantly with biomarker responses to colors.

There is a connection between higher testosterone concentration and better human performance $[9,22]$ and improved muscle function [16, 32]. Also, the color red is associated with higher testosterone [17] and physiological arousal level [51], but it is unknown if a surrounding red environment can influence testosterone concentration and exercise performance. Thus, we evaluated the acute effect of wearing colored-lens glasses on YoYolE2 performance, testosterone concentration, and other physiological indicators. We hypothesized that glasses with red lenses would increase both the testosterone concentration and exercise performance.

\section{Methods}

\section{General procedures and experimental design}

The local Ethical Committee for Human Experiments approved the current research accordingly [27], and the participants signed an informed consent form before the procedures. The participants attended the laboratory four times ( 2 to 4 days in between). On the first visit a screening, anthropometric measurements, and familiarization with the procedures (i. e., tried the googles and received explanations) were performed. Participants presented a medical statement confirming they did not have any eye disease and could view the colors correctly. Additional exclusion criteria included anyone using ergogenic or androgenic anabolic steroids or incapable of performing the tests proposed.

On the other three visits, the participants performed in a counterbalanced manner the YoYolE2 test (indoor sports court, $26 \pm 2^{\circ} \mathrm{C}$, humidity $=50 \pm 4 \%$ ) using protective goggles. The participants were invited to abstain from strenuous physical activity for at least $48 \mathrm{~h}$ before sessions and from food and caffeine intake for at least 3 and $12 \mathrm{~h}$, respectively, before all sessions [13, 14, 41]. All test sessions were performed between 3 and 4 p.m. (standardized for each) and conducted by the same experienced researcher.

\section{Participants}

Based on previous research [5] and the within-participants design, a sample size between 6 and 9 participants was sufficient to detect a significant $(p<0.05)$ difference among soccer playing positions ("group") in the YoYolE2. To counteract any dropout, a sample of 10 male amateur soccer players ([mean \pm SD] $21 \pm 1.1$ years, $1.75 \pm 0.05 \mathrm{~m}, 71.9 \pm 9.8 \mathrm{~kg}, 11 \% \pm 3$ body fat, playing experience $13 \pm 2$ years) participated in the current study.

\section{Protective goggles and sports court illuminance}

The players performed the YoYolE2 test wearing protective goggles (HDE ${ }^{\circledR}$, Germany): blue lenses (wavelength $\left.470 \mathrm{~nm}\right)$, red lenses (wavelength $660 \mathrm{~nm}$ ) and clear lenses (no protection wavelength, "sham"). No players reported discomfort or had an issue with the glasses falling off during the strenuous exercise. The sports court illuminance was recorded on each test day using a lux meter (Gama scientific ${ }^{\circledR}$, Landsberg am Lech, Germany). 


\section{Perceived recovery status}

To ensure the participants were in the same recovery condition before each trial, all volunteers indicated a score on a perceived recovery scale [34]. The scale ranged from 0 ("very poorly recovered, extremely tired") to 10 ("very well recovered, highly energetic") in arbitrary units $(\mathrm{AU})$ to rate their relative physical recovery. If the player scored 4 or less (somewhat recovered) for his recovery status, he was excluded from the day's session and was invited to return on another day.

\section{Blood samples for testosterone}

Before and 30 min after each YoYolE2, venous blood samples ( $5 \mathrm{~mL}$ ) were collected by a technician (median cubital vein) for testosterone analysis. Testosterone level was quantified in duplicate by electrochemiluminescence immunoassay (COBAS 6000 analyzers series, Roche Diagnostics Ltd., Rotkreuz, Switzerland).

\section{YoYo intermittent endurance test level 2 (YoYolE2)}

All players were familiar with the YoYolE2. Before the test, players performed a warm-up consisting of the first three running bouts of the YoYolE2 test followed by a period of lower-extremity stretching. The YoYolE2 test consists of a repeated $2 \times 20$ - m shuttle run at progressively increasing speed stages (initial speed $\sim 12 \mathrm{~km} \cdot \mathrm{h}^{-1}$ ), guided by specific audio signals ( $\mathrm{s}$ to recovery in a marked $2.5 \times 2$ - $\mathrm{m}$ area after the finishing line). Cessation of the test was assessed by failure to reach the finish line by the tone on two occasions [5]. Total distance covered was recorded. The volunteers performed the YoYolE2 test individually, and they received similar verbal encouragement during the tests. To prevent placebo/nocebo effect, a potential issue in ergogenic aids studies $[11,36,37,39]$, we informed the volunteers that all protective goggles could improve performance and none of them could be harmful. Also, we kept the participants blinded to data; i. e., no information about distance covered (the audio of speed and level of YoYolE2 was in an unknown language), HR and blood lactate [35].

\section{Heart rate, the rate of perceived exertion, and blood lactate concentration}

The heart rate (HR) was monitored (Polar ${ }^{\circledR}$ RS800CX, Helsinki, Finland) throughout the entire YoYolE2. After the YoYolE2, the participants remained seated wearing the goggles for HR recording (recovery). Just after the YoYolE2, the player indicated (individually to prevent bias) a score for his rate of perceived exertion (RPE) via the Borg CR10 scale ranging from 0 ("nothing at all") to 10 ("very very hard") to determine the internal intensity of the session [3]. In the $3^{\text {rd }}$ minute after the test, a blood sample $(25 \mu \mathrm{L})$ was collected from the fingertip to measure the lactate concentration using a valid [18] portable analyzer (ROCHE ${ }^{\circledR}$ Accu-Check, Basel, Switzerland).

\section{Data analysis}

The Shapiro-Wilk test was applied to verify the data's normality of distribution. We did a repeated measures one-way analysis of variance (ANOVA) for within-participants analysis (parametric) or Friedman test (nonparametric data), with Tukey and Dunn tests as post-hoc tests. The effect sizes (Cohen's d) were calculated to de- termine the magnitude of practical relevance (only for significant, i. e., $\alpha$ value of $\leq 0.05$ result) and were interpreted as small (0.2), medium (0.5) and large (0.8), as suggested [6]. For the testosterone values (pre- and postcondition in each trial), a two-way ANOVA was conducted followed by Sidak's post-test. Data are presented as mean $\pm S D$.

\section{Results}

The illuminance of the sports court was similar (Friedman test, $p=0.1$ ) for each of the three conditions ( 101 lux). The score on the perceived recovery scale before each trial also did not differ (Friedman test, $\mathrm{p}=0.9$ ) among the three trials (colorless: $7.5 \pm 1.5 \mathrm{AU}$; blue: $6.8 \pm 2.4 \mathrm{AU}$; red: $7.0 \pm 1.9 \mathrm{AU}$ ).

The distance covered in the YoYolE2 performance did not differ (ANOVA, $p=0.7$ ) among the three trials ( $\vee$ Fig. $\mathbf{1}$ ) and the players covered $\sim 930 \mathrm{~m}$ (mean of three trials). The rating of perceived exertion immediately after the YoYolE2 also did not differ (Friedman test, $\mathrm{p}=0.99$ ) among conditions: control $8.6 \pm 1.2 \mathrm{AU}$; blue: $8.7 \pm 1.3 \mathrm{AU}$ and red: $8.4 \pm 1.3 \mathrm{AU}$.

Relative HR (\% of maximum) during the exercise did not differ $(p>0.05)$ among trials (ANOVA, \%HR max : control: $95 \pm 6$; blue: $92 \pm 7$; red: $97 \pm 6$ ). The delta HR values (difference between resting $\mathrm{HR}$ and during the analyzed time) was significantly different among conditions (ANOVA, $p<0.05$, effect size 0.89 ) in the $1^{\text {st }}$ minute post-test (lower in blue than red glasses - $>$ Fig. 2).

In relation to the baseline values (delta: post - pre YoYolE2), following the red-lensed condition testosterone concentration increased by $\sim 14 \pm 7 \%$, which was higher (Friedman test, $p=0.01$, effect sizes 0.95 and 0.56 , respectively) than colorless $(0.9 \pm 2 \%)$ and blue lenses $(5 \pm 3 \%)$. The absolute testosterone concentration was elevated (two-way ANOVA, $p<0.05$, effect size $=0.75$ ) in relation to the baseline values after the red-lensed condition, but no differences were found $(p>0.05)$ in either the control or bluelensed conditions ( $\vee$ Fig. $\mathbf{3}$ ).

The blood lactate concentrations (measured 3 min post-test) did not differ (ANOVA, $\mathrm{p}=0.21$ ) among conditions (colorless: $10.2 \pm 1.2 \mathrm{mmol} / \mathrm{L}$; blue: $9.9 \pm 4.1 \mathrm{mmo} / \mathrm{L}$; red: $8.6 \pm 3.1 \mathrm{mmol} / \mathrm{L})$.

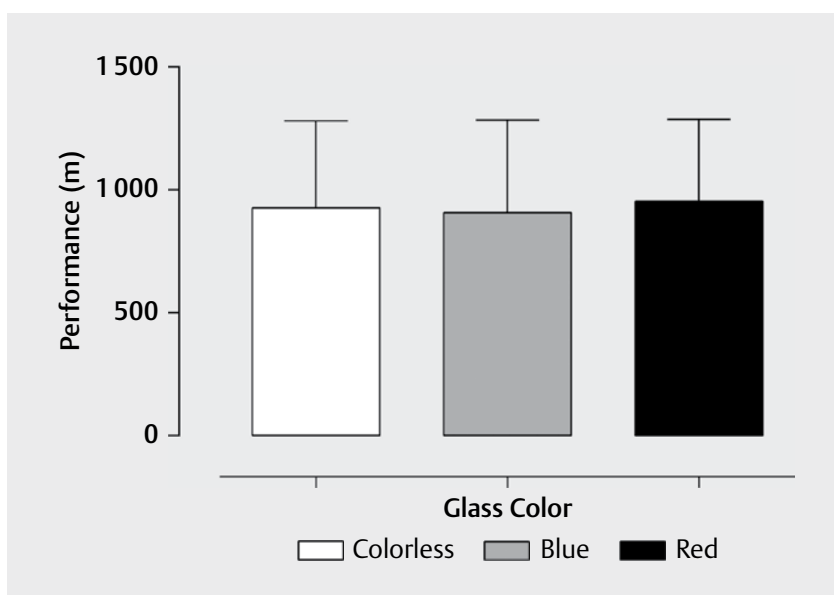

Fig. 1 Distance covered $(\mathrm{m})$ for YoYolE2 in each color condition. Values are mean \pm SD. 


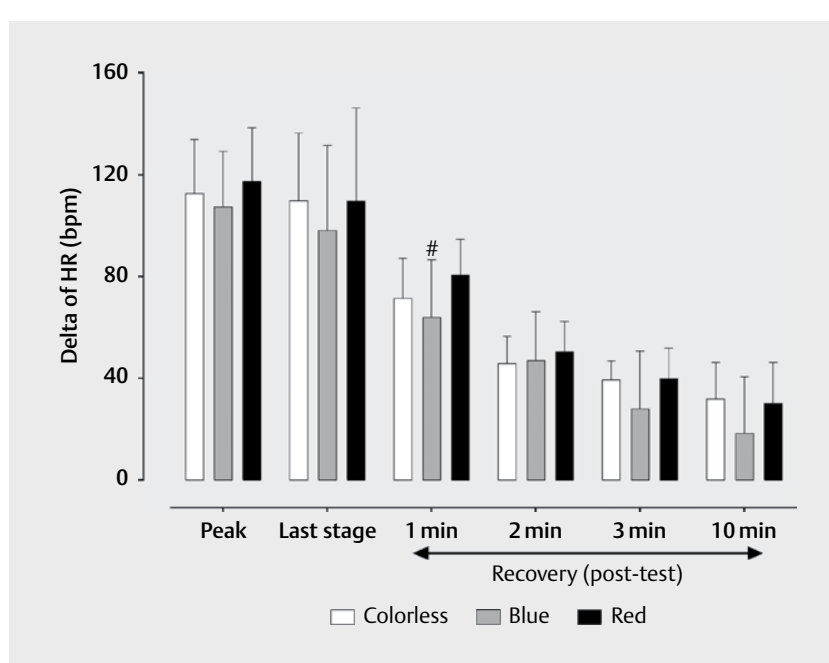

- Fig. 2 Delta of hear rate (HR) difference between resting HR and during the analyzed time. \# $\mathrm{p}<0.05$ in comparison with red lenses. Values are mean \pm SD.

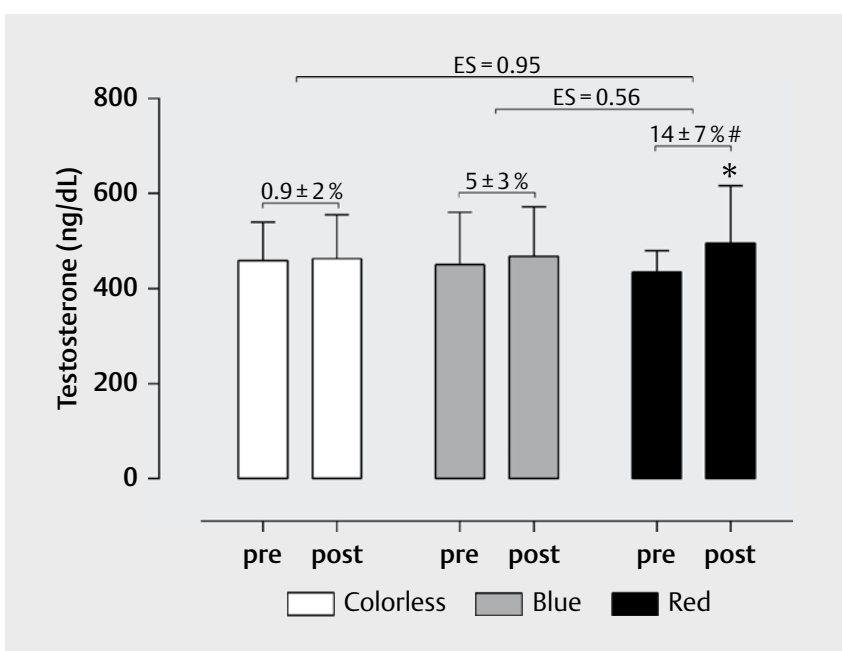

- Fig. 3 Absolute blood testosterone levels pre- and post-YoYolE2 for each color condition. Values are mean \pm SD; ${ }^{*}$ means $p<0.05$ vs pre-test (effect size $=0.75$ ). The percentage numbers above the bars are delta (\% difference between post - pre values); \# red lensed condition higher $(p=0.01)$ than both other conditions; $E S=$ effect sizes.

\section{Discussion}

This study is the first to test the acute effects of wearing glasses with colored lenses on high-intensity intermittent exercise performance and metabolic responses. It is also the only study to explore the effect of colors on exercise performance while controlling for ambient illuminance and recovery status of the participants, both of which are fundamental to rigorous research design. Our main findings were that colored lenses did not influence YoYolE2 performance (distance covered); however, the red-lensed condition showed increased blood testosterone concentration. The lack of effect of the color on physical performance is in contrast with pre- vious research $[8,19,44]$. This discrepancy is likely a result of the type of exercise.

The YoYolE2 represents a high-intensity exercise demanding near maximum physiological indicators. For example, a study showed responses of heart rate of $\sim 99 \%$ of maximum, blood lactate $\sim 10 \mathrm{mmol} / \mathrm{L}$, decrements of $\sim 24 \%$ in muscle glycogen and $\sim 70 \%$ muscle phosphocreatine in non-elite practitioners [33]. Besides, the YoYolE2 is highly specific to soccer demands, including changes of direction and acceleration/deceleration, which are inherent to soccer performance and thus appropriate for checking ergogenic effects. Previous research about color and performance has assessed strength and power outcomes. For instance, Fisher et al. showed that wearing blue-lensed glasses (compared to red or colorless) improved endurance performance in leg press resistance exercise in young healthy males [19]. In contrast, a room with red lighting (compared to blue or white light) improved performance in a Wingate anaerobic power test, whereas a room with white light produced greater handgrip strength test [8]. However, in other research college students exhibited greater grip strength in the presence of red visual stimulation (compared to green) [44]. Notably, none of those above studies measured potentially mechanistic physiological variables such as testosterone and so comparison to the present research is impossible.

Our data supported that the YoYolE2 promoted maximal effort by the participants (e. g., the rate of perceived exertion $>8$ on a scale $0-10$ and $92-97 \%$ of $H R_{\max }$ ) during the three trials, which is appropriate because the YoYolE2 is considered a maximal-intensity exercise. The distance covered in the current study $(\sim 930 \pm 355 \mathrm{~m}$ - mean of the trials) was higher than untrained individuals $(665 \pm 271 \mathrm{~m})$ but lower than trained $(2027 \pm 298 \mathrm{~m})$ soccer players [33]. Because our sample included young, amateur soccer players, our results are in agreement with the previous literature [35].

Our $\mathrm{HR} \%$ values are similar to those reported in previous research on elite under 19-year-old soccer players $(\sim 94.5 \% \pm 6.8)$ [5]. Also, the absence of differences among color trials in perceived exertion (maximal effort) is consistent with previous research [19].

We found lower delta HR values for the color blue in comparison to red in the first minute of recovery after YoYolE2. Although Fisher et al. (2015) reported similar HR values for red, blue and colorless conditions, they did not record HR during recovery. Furthermore, because the present study tested high-intensity intermittent exercise rather than a resistance exercise task, comparisons with similar research is not possible. However, there is tenuous support for an increase in parasympathetic activity, which might serve to reduce HR faster. Authors reported that using a blue partition board reduced task-induced subjective fatigue, possibly by increasing autonomic reactivity [47]. Thus, we speculate that within the present study there was an influence of the blue color on the autonomic nervous system (i. e., increasing parasympathetic activity), reducing $\mathrm{HR}$ faster post-exercise. In fact, the blue color has been associated with activation of the parasympathetic nervous system, reducing heart rate [30]. From a practical application, a faster recovery following high-intensity exercise could be beneficial for several sports. Future studies measuring parasympathetic and sympathetic activities could check for possible adaptive effects of long-term training with the use of blue-lensed glasses on HR response. Within our study, there were no statistical differences for 
HR delta 2, 3, and 10 min post-test, suggesting that autonomic activity had already affected the reduction in HR (i. e., blue-lensed glasses had no continued effect).

We found that the red color-lensed condition resulted in increased blood testosterone concentration post-test, advancing the understanding of the previous research that associated wearing red with better performance [28] or active choice of red with higher basal testosterone levels [17]. This was in contrast to the bluelensed (effect size 0.56 - medium) and control-lensed (effect size 0.95 - large) conditions. The large effect size found could be promising for practical application, once studies have associated performance and testosterone $[7,22,46]$. However, the present study does not confirm such a positive relationship because YoYolE2 performance was not improved. Maybe the nature of YoYolE2, i. e., intermittent maximal test, including acceleration/deceleration, changes of direction, eccentric actions involved, might counterbalance the acute effect of higher testosterone. Future studies could investigate whether this testosterone increase could positively influence performance later in the same day, as others have found for power exercises [7]. Furthermore, because the use of red-lensed glasses during chronic exercise (i. e., physical training) has not been evaluated to date, future research should consider specific cases where elevated testosterone levels might be beneficial. For instance, a study involving 2587 men (aged 65 to 99 years) showed that fall risk was higher in men with lower bioavailable testosterone levels "independent" of physical performance [45].

The blood lactate concentration did not differ among conditions. Although no previous study has evaluated the effects of color on post-exercise blood lactate, the similar results among colors make sense because blood lactate is related to the intensity of exercise, and we did not find differences among colors in the distance covered, HR\% or rate of perceived exertion. Furthermore, the post-test values of $\sim 10 \mathrm{mmol} / \mathrm{L}$ resemble those found in another study [33].

As limitations of the present study, we could highlight: the absence of measurements to explain the mechanisms underpinning increased testosterone levels for red lenses (e. g., light perception, retinohypothalamic pathway), and the accurate measure of parasympathetic activation to check the effect of blue lenses on $\mathrm{HR}$ recovery. The sample size was relatively small $(n=10)$ and could generate a type II error and does not permit playing position comparisons that would be appropriate for soccer $[12,49]$. Another potential limitation could be related to the lack of a non-exercising control condition. However, we used a crossover design (including blood samples collected before and after each condition) to minimize these limitations. Additionally, our study adds to our understanding of the association among color, human performance, and related indicators.

In summary, our results suggest that (acute) wearing colored lenses does not influence high-intensity intermittent exercise performance and internal intensity indicators (rate of perceived exertion and $\mathrm{HR}$ responses) in amateur soccer players. However, wearing red-colored lenses during high-intensity intermittent exercise increases testosterone concentration after the session, and blue color seems to increase parasympathetic activity, improving HR recovery.

\section{Conflicts of Interest}

The authors declare that they have no conflict of interest

\section{Acknowledgment}

This work was supported by the State Funding Agency of Minas Gerais, Brazil (FAPEMIG). The funders had no role in study design, data collection, and analysis, decision to publish, or preparation of the manuscript

\section{References}

[1] Andersson S, Pryke SR, Ornborg J, Lawes MJ, Andersson M. Multiple receivers, multiple ornaments, and a trade-off between agonistic and epigamic signaling in a widowbird. Am Nat 2002; 160: 683-691

[2] Attrill M], Gresty KA, Hill RA, Barton RA. Red shirt colour is associated with long-term team success in English football. J Sports Sci 2008; 26: 577-582

[3] Borg E, Kaijser L. A comparison between three rating scales for perceived exertion and two different work tests. Scand J Med Sci Sports 2006; 16: 57-69

[4] Bradley PS, Bendiksen M, Dellal A, Mohr M, Wilkie A, Datson N, Orntoft C, Zebis M, Gomez-Diaz A, Bangsbo J, Krustrup P. The application of the Yo-Yo intermittent endurance level 2 test to elite female soccer populations. Scand J Med Sci Sports 2014; 24: 43-54

[5] Bradley PS, Mohr M, Bendiksen M, Randers MB, Flindt M, Barnes C, Hood P, Gomez A, Andersen JL, Di Mascio M, Bangsbo J, Krustrup P. Sub-maximal and maximal Yo-Yo intermittent endurance test level 2: Heart rate response, reproducibility and application to elite soccer. Eur J Appl Physiol 2011; 111: 969-978

[6] Cohen J. Quantitative methods in psychology. A power primer. Psychol Bulletin of the Psychonomic Society 1992; 112: 155-159

[7] Cook C], Kilduff LP, Crewther BT, Beaven M, West D]. Morning-based strength training improves afternoon physical performance in rugby union players. J Sci Med Sport 2014; 17: 317-321

[8] Crane DK, Hensarling RW, Jung AP, Sands CD, Petrella JK. The effect of light color on muscular strength and power. Percept Mot Skills 2008; 106: 958-962

[9] Crewther BT, Cook C], Lowe TE, Weatherby RP, Gill N. The effects of short-cycle sprints on power, strength, and salivary hormones in elite rugby players. J Strength Cond Res 2011; 25: 32-39

[10] Cruz TMFd, Germano MD, Crisp AH, Sindorf MAG, Verlengia R, da Mota GR, Lopes CR. Does Pilates training change physical fitness in young basketball athletes? J Exerc Physiol Online 2014; 17: 1-9

[11] da Mota GR, Marocolo M. The effects of ischemic preconditioning on human exercise performance: A counterpoint. Sports Med 2016; 46: 1575-1576

[12] da Mota GR, Thiengo CR, Gimenes SV, Bradley PS. The effects of ball possession status on physical and technical indicators during the 2014 FIFA World Cup Finals. J Sports Sci 2016; 34: 493-500

[13] da Silva BV, Simim MA, Marocolo M, Franchini E, da Mota GR. Optimal load for the peak power and maximal strength of the upper body in Brazilian Jiu-jitsu athletes. J Strength Cond Res 2015; 29: 1616-1621

[14] da Silva BV, Ide BN, de Moura Simim MA, Marocolo M, da Mota GR. Neuromuscular responses to simulated Brazilian jiu-jitsu fights. J Hum Kinet 2014; 44: 249-257 
[15] Duffield R, Murphy A, Kellett A, Reid M. Recovery from repeated on-court tennis sessions: Combining cold-water immersion, compression, and sleep recovery interventions. Int J Sports Physiol Perform 2014; 9: 273-282

[16] Estrada M, Espinosa A, Muller M, Jaimovich E. Testosterone stimulates intracellular calcium release and mitogen-activated protein kinases via a $\mathrm{G}$ protein-coupled receptor in skeletal muscle cells. Endocrinology 2003; 144: 3586-3597

[17] Farrelly D, Slater R, Elliott HR, Walden HR, Wetherell MA. Competitors who choose to be red have higher testosterone levels. Psychol Sci 2013; 24: 2122-2124

[18] Fell JW, Rayfield JM, Gulbin JP, Gaffney PT. Evaluation of the Accusport lactate analyser. Int J Sports Med 1998; 19: 199-204

[19] Fisher J, D'Amario D, Small C, Stopforth M. Effect of colored lenses on muscular performance. J Sports Med Phys Fitness 2015; 55: 549-556

[20] García-Rubio MA, Picazo-Tadeo A], González-Gómez F. Does a red shirt improve sporting performance? Evidence from Spanish football. Appl Econ Lett 2011; 18: 1001-1004

[21] Garcia CA, da Mota GR, Marocolo M. Cold water immersion is acutely detrimental but increases performance post- $12 \mathrm{~h}$ in rugby players. Int J Sports Med 2016; 37: 619-624

[22] Gaviglio CM, Crewther BT, Kilduff LP, Stokes KA, Cook C]. Relationship between pregame concentrations of free testosterone and outcome in rugby union. Int J Sports Physiol Perform 2014; 9: 324-331

[23] Gleeson M, Bishop NC. Elite athlete immunology: Importance of nutrition. Int J Sports Med 2000; 21: (Suppl 1): S44-S50

[24] Greenlees I, Leyland A, Thelwell R, Filby W. Soccer penalty takers' uniform colour and pre-penalty kick gaze affect the impressions formed of them by opposing goalkeepers. J Sports Sci 2008; 26 : 569-576

[25] Greenlees IA, Eynon M, Thelwell RC. Color of soccer goalkeepers' uniforms influences the outcome of penalty kicks. Percept Mot Skills 2013; 117: 1043-1052

[26] Hackney AC. Testosterone and human performance: Influence of the color red. Eur J Appl Physiol 2006; 96: 330-333

[27] Harriss DJ, Macsween A, Atkinson G. Standards for ethics in sport and exercise science research: 2018 update. Int J Sports Med 2017; 38: $1126-1131$

[28] Hill RA, Barton RA. Psychology: Red enhances human performance in contests. Nature 2005; 435: 293

[29] Hopkins WG, Hawley JA, Burke LM. Design and analysis of research on sport performance enhancement. Med Sci Sports Exerc 1999; 31: 472-485

[30] Kaiser PK. Physiological response to color: A critical review. Color Res Appl 1984; 9: 8

[31] Kilian Y, Engel F, Wahl P, Achtzehn S, Sperlich B, Mester J. Markers of biological stress in response to a single session of high-intensity interval training and high-volume training in young athletes. Eur J Appl Physiol 2016; 116: 2177-2186

[32] Krotkiewski M, Kral JG, Karlsson J. Effects of castration and testosterone substitution on body composition and muscle metabolism in rats. Acta Physiol Scand 1980; 109: 233-237

[33] Krustrup P, Bradley PS, Christensen JF, Castagna C, Jackman S, Connolly L, Randers MB, Mohr M, Bangsbo J. The Yo-Yo IE2 test: Physiological response for untrained men versus trained soccer players. Med Sci Sports Exerc 2015; 47: 100-108

[34] Laurent CM, Green JM, Bishop PA, Sjokvist J, Schumacker RE, Richardson MT, Curtner-Smith M. A practical approach to monitoring recovery: Development of a perceived recovery status scale. J Strength Cond Res 2011; 25: 620-628
[35] Marocolo IC, da Mota GR, Londe AM, Patterson SD, Barbosa Neto O, Marocolo M. Acute ischemic preconditioning does not influence high-intensity intermittent exercise performance. Peer] 2017; 5: e4118

[36] Marocolo M, Coriolano HA, Mourao CA, da Mota GR. Crucial points for analysis of ischemic preconditioning in sports and exercise. Med Sci Sports Exerc 2017; 49: 1495-1496

[37] Marocolo M, da Mota GR, Pelegrini V, Appell Coriolano HJ. Are the beneficial effects of ischemic preconditioning on performance partly a placebo effect? Int J Sports Med 2015; 36: 822-825

[38] Marocolo M, da Mota GR, Simim MA, Appell Coriolano HJ. Myths and facts about the effects of ischemic preconditioning on performance. Int J Sports Med 2016; 37: 87-96

[39] Marocolo M, Marocolo IC, da Mota GR, Simao R, Maior AS, Coriolano $\mathrm{HJ}$. Beneficial effects ofischemic preconditioning in resistance exercise fade over time. Int J Sports Med 2016; 37: 819-824

[40] Marocolo M, Willardson JM, Marocolo IC, da Mota GR, Simao R, Maior AS. Ischemic Preconditioning and placebo intervention improve resistance exercise performance. J Strength Cond Res 2016; 30: 1462-1469

[41] Meneghel AJ, Verlengia R, Crisp AH, Aoki MS, Nosaka K, da Mota GR, Lopes CR. Muscle damage of resistance-trained men after two bouts of eccentric bench press exercise. J Strength Cond Res 2014; 28 : 2961-2966

[42] Mota GR, Gomes LH, Castardeli E, Bertoncello D, Vicente EJD, Marocolo M, Orsatti FL. Treinamento proprioceptivo e de força resistente previnem lesões no futebol. J Health Sci Inst 2010; 28 : 191-193

[43] Mota GR, Magalhães CG, PHSM Azevedo, Ide BN, Lopes CR, Castardeli E, Bartosa Neto O, Marocolo M, Baldissera V. Lactate threshold in taekwondo through specifics tests. J Exerc Physiol Online 2011; 14: 60-66

[44] O'Connell B], Harper RS, McAndrew FT. Grip strength as a function of exposure to red or green visual stimulation. Percept Mot Skills 1985; 61: 1157-1158

[45] Orwoll E, Lambert LC, Marshall LM, Blank J, Barrett-Connor E, Cauley ], Ensrud K, Cummings SR. Osteoporotic Fractures in Men Study G. Endogenous testosterone levels, physical performance, and fall risk in older men. Arch Intern Med 2006; 166: 2124-2131

[46] Russell M, King A, Bracken RM, Cook C], Giroud T, Kilduff LP. A Comparison of different modes of morning priming exercise on afternoon performance. Int J Sports Physiol Perform 2016; 11: 763-767

[47] Sakuragi S, Sugiyama Y. Effect of partition board color on mood and autonomic nervous function. Percept Mot Skills 2011; 113: 941-956

[48] Setchell JM, Dixson AF. Changes in the secondary sexual adornments of male mandrills (Mandrillus sphinx) are associated with gain and loss of alpha status. Horm Behav 2001; 39: 177-184

[49] Simim MAM, Silva BVC, Marocolo Júnior M, Mendes EL, de Mello MT, Mota GR. Anthropometric profile and physical performance characteristic of the Brazilian amputee football (soccer) team. Motriz: Rev Educ Fís 2013; 19: 641-648

[50] Sorokowski P, Szmajke A. The influence of the "red win" effect in sports: A hypothesis of erroneous perception of opponents dressed in red - preliminary test. Hum Mov 2011; 12: 367-373

[51] Wright HR, Lack LC, Kennaway D]. Differential effects of light wavelength in phase advancing the melatonin rhythm. J Pineal Res 2004; 36: 140-144 